\title{
NUMERICAL INVESTIGATION OF GLASS-FIBER REINFORCED PLASTIC MORTAR PIPES CULVERT RESPONSE TO HEAVY TRUCK LOADS
}

\author{
Huawang Shi, Chencheng Gu,Chongchong Xue and Yancang Li \\ Hebei University of Engineering, School of Civil Engineering, Handan, Hebei 056038, \\ China; stone21st@163.com
}

\begin{abstract}
The main objective of this paper is to investigate the dynamic performance and behaviour of glass-fiber reinforced plastic (GRP) mortar pipes under heavy truck loads. According to the field conditions, a finite element dynamic analysis (FEDA) model of GRP pipe culverts was established. Modal analysis of the vibration system was carried out, and the main natural frequencies with $26.6 \mathrm{~Hz}, 32 \mathrm{~Hz}, 35.7 \mathrm{~Hz}$ and corresponding mode shapes were obtained. On the basis of modal analysis, dynamic response of GRP pipe culverts under vehicle loads was simulated through random vibration. Based on the measured vibration velocity time histories, the modal and random vibration responses of the vibration system were analyzed. The results show that the spectral response value of pipeline to vehicle load decreases with the increase of buried depth. When the depth of GRP pipe culverts buried is greater than $0.8 \mathrm{~m}$, the influence of ground vehicle dynamic loads on the vibration of GRP pipe culverts cannot be taken into consideration. It can provide the basis for the design of GRP pipe culverts, especially under heavy loads.
\end{abstract}

\section{KEYWORDS}

GRP mortar pipe culvert, Finite element analysis, Dynamic response, Vibration properties

\section{INTRODUCTION}

Glass-fiber reinforced plastic (GRP) mortar pipe is a kind of new composite materials using resin as matrix material, glass fiber and its products as reinforced material, including quartz sand as filling material made of a certain process. In the 1970s, GRP mortar pipe was developed. As a new type of flexible pipe, it has been widely used in the world due to its good performance such as strong corrosion resistance, high strength, light weight, etc. After confirming that GRP mortar pipe is particularly suitable for underground pipeline, many countries began to apply GRP mortar pipe in municipal drainage and drainage, highway culvert and other fields [1,2].

In the 1960s and 1970s, numerous studies have been conducted on the interaction between pipeline and soil. In 1975, Newmark [3] presented the vibration of the buried pipe. He assumed that the pipe and the surrounding soil were a whole and moved together under the vibration load. According to R. A. Parmelee's study [4], the static Mindlin method was used to calculate the interaction between pipe and soil; $T$. Zhang et al. $[5,6]$ collected and analyzed a large number of statistical data to find out the causes and solutions of damage and leakage, and then used the original parameter method of elastic semi-infinite plane foundation beam to verify the statistical results.

With the popularization and application of finite element mechanical analysis software, J. Lee [7] simulated the failure of GRP under internal pressure by using finite element analysis software. The results show that the finite element analysis software can be used for the failure 
analysis of GRP under lower internal pressure. In 1989, J. Jeyk [8] presented a finite element model of GRP mortar pipe by using the finite element analysis software. In this model, the problem of pipe soil contact is considered, and an example is analyzed with this model to summarize the causes of pipe failure. A numerical analysis model of GRP mortar pipe based on ABAQUS was established and its dynamic response under seismic load was investigated and the results are reported in the L. Xu, and Z.C. Ye [9]. Manko and Beben [11,12] measured the strain and vibration velocity of the steel bellows culvert under the dynamic load condition of passing through the vehicle at the speed of $10-70 \mathrm{~km} / \mathrm{h}$. B. Flener and Karoumi [13] conducted an experimental study on culverts under railway dynamic load. The displacement and strain of the culvert are measured, and the dynamic amplification factor (DAF) is calculated.

At present, most of the dynamic response analysis of bridge and culvert structure is based on the method of field test, which is easily affected by various adverse factors such as cost and environment. In this paper, details including the dynamic response of the buried GRP mortar pipe by using the random vibration module based on the ANSYS Workbench finite element analysis software are discussed. First, the numerical analysis model of GRP mortar pipe is established by workbench, and the corresponding main natural frequencies and modes are obtained by modal analysis. Then the dynamic response of the buried pipe under different working conditions is simulated by the random vibration module. Finally, based on the field measurement data, the feasibility of using workbench random vibration module to analyze the frequency response of buried pipe is verified. It can provide the basis for the safety of engineering design under heavy load, and for the designers to determine the natural frequency and vibration mode of the buried pipe, so as to avoid resonance in the structural design of the buried pipe, and predict the vibration form of the buried pipe under different working conditions in the construction stage.

\section{METHODS}

\section{Preparation method of ANSYS}

According to the full-field test, the ANSYS finite element numerical model is used to simulate the stress state of pipe culvert. The model size is $10 \mathrm{~m} \times 6 \mathrm{~m} \times 6 \mathrm{~m}$ (length $\times$ height $\times$ width). The length of pipe is $6 \mathrm{~m}$ with $1.5 \mathrm{~m}$ diameter and $0.05 \mathrm{~m}$ wall thickness $[13,14]$. The thickness of the pipe wall is much smaller than the pipe diameter, so shell element is used to simulate. The soil is analyzed by 3D solid element $[15,16]$.

\section{Boundary condition}

After the numerical model is established, reasonable boundary conditions are applied. In the rectangular soil model, the horizontal displacement constraint is applied to the front and back facades, the horizontal displacement constraint is applied to both sides of the soil, and the full constraint is applied to the bottom.

\section{Contraction between pipe and soil}

The material characteristics of backfill and original soil are quite different. The soil is set as elastic system with two-layer: the upper layer is backfilling, and the lower layer is original soil. The vehicle load acts on the pipe indirectly through the soil. Therefore, it is necessary to consider the contact action between the pipe and the soil when establishing the finite element dynamic analysis model of the GRP mortar pipe culvert. In addition to transferring the pressure between the pipe and the soil, there are also friction and relative displacement between the pipe and the soil. In order to describe the nonlinear characteristics of the soil, the soil is set as the target surface, the pipeline as the contact surface, the contact surface between the pipe body and the backfill and the original soil is set as the friction surface, and the friction coefficient is set as 0.15 ; the contact surface between the backfill and the original soil is set as the bond contact; the model applies the gravity 
acceleration perpendicular to the road surface as a whole $\left(g=9.8 \mathrm{~m} / \mathrm{s}^{2}\right)$; and the soil constitutive model is the Drucker-Prager(D-P) nonlinear elastic model in finite element analysis. Due to considering the internal friction angle and cohesion of soil, the D-P constitutive model can reflect the nonlinear characteristics of soil.

\section{Material property parameters}

The influence of inertia force and damping should be considered in dynamic analysis under the condition of fast loading and impact. This topic analyzes the vibration load of the buried pipe when the vehicle passes through the road, so the influence of damping is ignored. The inertia of the structure should be considered in the dynamic response analysis. The mechanical parameters such as bulk density, modulus of elasticity and Poisson's ratio are given through experiments as shown in Table 1.

Tab. 1 - Material parameters.

\begin{tabular}{|c|c|c|c|c|c|c|c|c|c|}
\hline Constituents & $\begin{array}{c}\text { Unit weight } \\
\mathrm{\rho} /\left(\mathrm{kg} \cdot \mathrm{m}^{-3}\right)\end{array}$ & $\begin{array}{c}\text { Poisson's } \\
\text { ratio }\end{array}$ & $\begin{array}{c}\text { Modulus of } \\
\text { elasticity } \\
\mathrm{E} / \mathrm{MPa}\end{array}$ & $\begin{array}{c}\text { Internal } \\
\text { friction } \\
\text { angle } \\
\varphi /{ }^{\circ}\end{array}$ & $\begin{array}{c}\text { Cohesion } \\
\mathrm{c} / \mathrm{kPa}\end{array}$ & $\begin{array}{c}\mathrm{E}^{1} \\
/ \mathrm{MPa} a\end{array}$ & $\begin{array}{c}\mathrm{E}^{2}=\mathrm{E}^{3} \\
/ \mathrm{MPa}\end{array}$ & $\begin{array}{c}\mathrm{G}^{12}=\mathrm{G}^{13} \\
/ \mathrm{MPa}\end{array}$ & $\begin{array}{c}\mathrm{G}^{23} \\
/ \mathrm{MPa}\end{array}$ \\
\hline Backfill & 1940 & 0.3 & 32.4 & 26 & 20 & - & - & - & - \\
\hline Original soil & 1820 & 0.3 & 50 & 35 & 60 & - & - & - & - \\
\hline Pipe culvert & 1800 & 0.27 & - & - & - & 3210 & 8900 & 2800 & 1800 \\
\hline
\end{tabular}

Note: $E^{1}, E^{2}$ and $E^{3}$ are the elastic modulus in $X, Y$ and $Z$ directions respectively, and $G^{12}, G^{13}$ and $G^{23}$ are shear modulus in $X-Y, X-Z$ and $\mathrm{Y}$-Z plane respectively.

\section{RESULTS AND DISCUSSION}

\section{Field test}

The total length of the selected road is $33.8 \mathrm{~km}$, and the whole line is second-lass highway. The GRP mortar pipes with diameter of DN1500 and wall thickness of $50 \mathrm{~mm}$ are used as buried pipe culverts. In this test, the characteristic section of pipe culvert is selected as the test section, and the strain change rule of each test point of pipe culvert under different working conditions is tested by pasting strain gauge. In this experiment, the filling height of culvert top is $80 \mathrm{~cm}$ and $100 \mathrm{~cm}$ respectively, the weight of roller is $20 \mathrm{t}$, the weight of truck is $40 \mathrm{t}$ and $60 \mathrm{t}$ respectively, the front and rear wheel axle of truck with speed of $30 \mathrm{~km} / \mathrm{h}$ is directly above the pipe axis, and the truck is in the middle line of road as shown in Figure1.

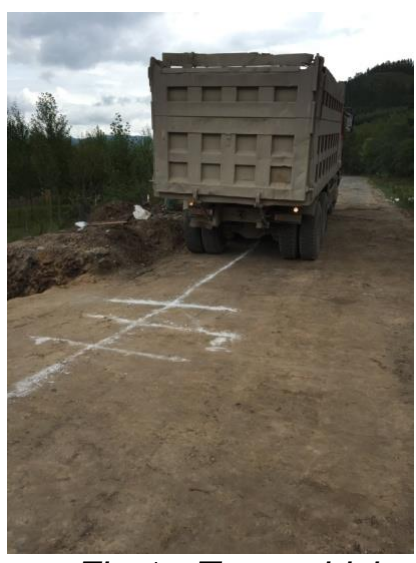

Fig.1 - Test vehicle

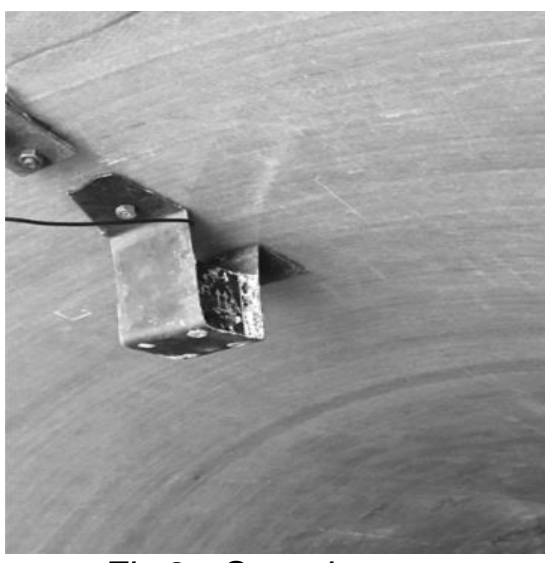

Fig.2 - Speed sensor 
The Q9 wire at the other end of the speed sensor as shown in Figure 2 is connected to four channels of the TST5925EV wireless telemetry dynamic strain analysis system. The sampling frequency is set at $50 \mathrm{~Hz}$, and the instrument is continuously sampled for debugging. After all channels are connected correctly, data collection begins.

\section{Test results}

The working condition of the buried pipe test is shown in Table 2.

\begin{tabular}{|c|c|c|}
\multicolumn{3}{|c}{ Tab. 2 - Working conditions } \\
\cline { 2 - 3 } Vehicle weight & \multicolumn{2}{|c|}{ Height of fill } \\
\cline { 2 - 3 } & Working condition $1 \#$ & Working condition 2\# \\
\hline $20 \mathrm{t}$ & Working condition 3\# & Working condition 4\# \\
\hline $40 \mathrm{t}$ & Working condition $5 \#$ & Working condition 6\# \\
\hline $60 \mathrm{t}$ &
\end{tabular}

Under working condition 1 (20t roller, filling height with $80 \mathrm{~cm}$ ), the vibration speed time history of the top and side of the GRP mortar pipe is as follows:

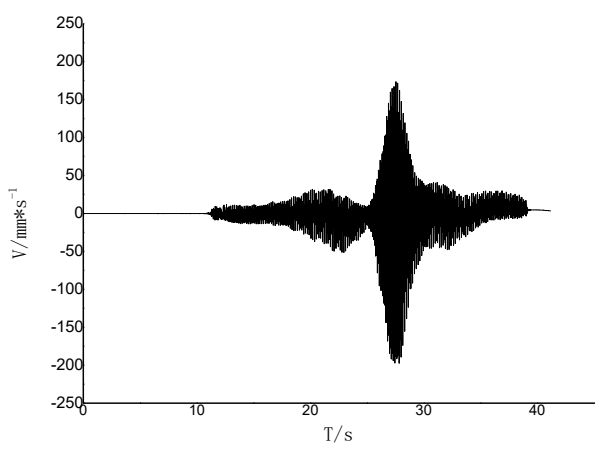

(a) Top

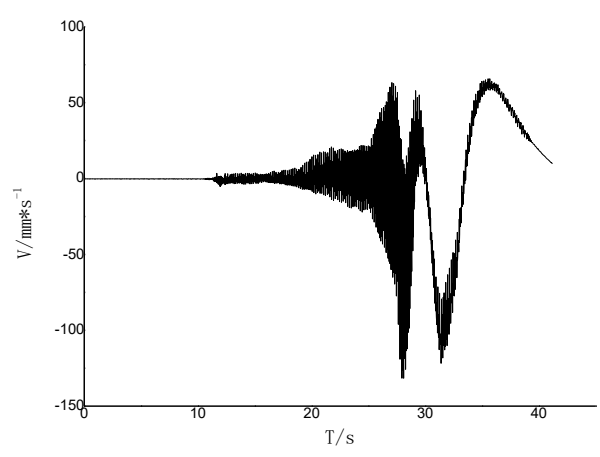

(b) Side

Fig.3 - Time history curve of vibration velocity under working condition 1

Under condition 2 (20t roller, filling height with $100 \mathrm{~cm}$ ), the vibration speed time history of pipe top and pipe side is as follows:

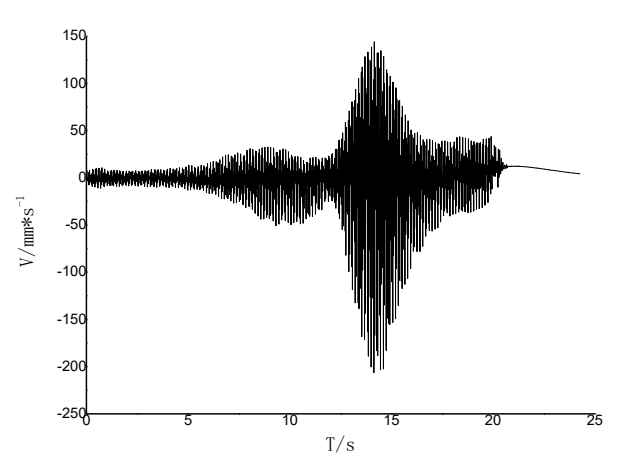

(a) Top

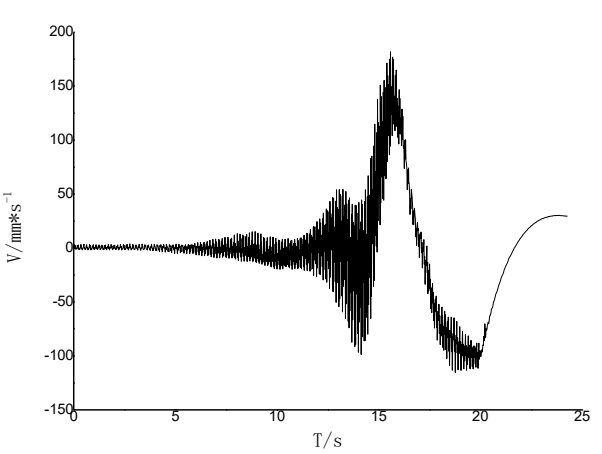

(b) Side

Fig. 4 - Time history curve of vibration velocity under working condition 2 
Under working condition 3 (40t truck, filling height with $80 \mathrm{~cm}$ ), the vibration speed time history of pipe top and pipe side is as follows:

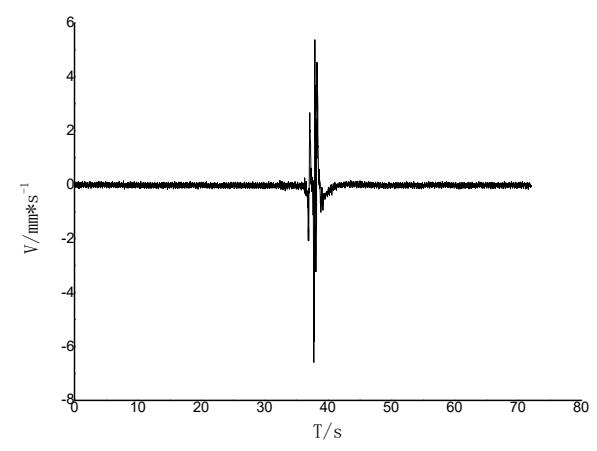

(a) Top

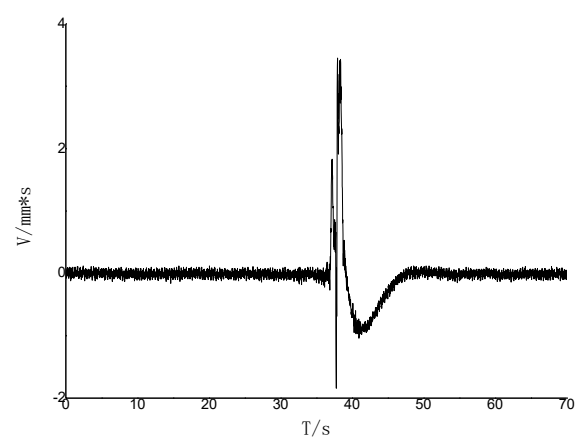

(b) Side

Fig.5 - Time history curve of vibration velocity under working condition 3

Under working condition 4 (40t truck, filling height with $100 \mathrm{~cm})$, the vibration speed time history of pipe top and pipe side is as follows:

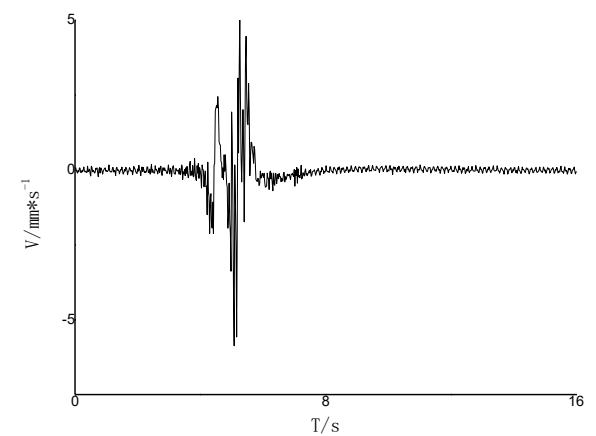

(a) Top

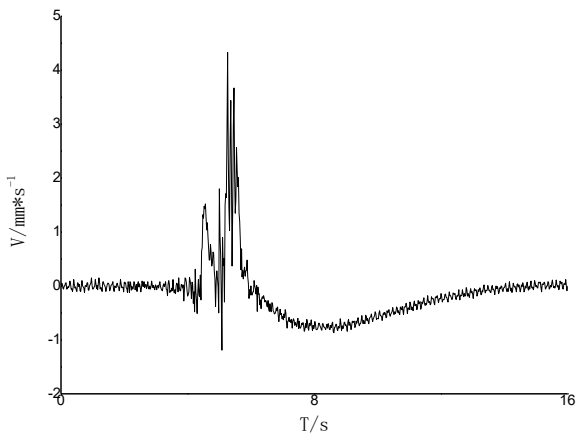

(b) Side

Fig. 6 - Time history curve of vibration velocity under working condition 4

Under working condition 5 (60t truck, filling height with $80 \mathrm{~cm}$ ), the vibration speed time history of pipe top and pipe side is as follows:

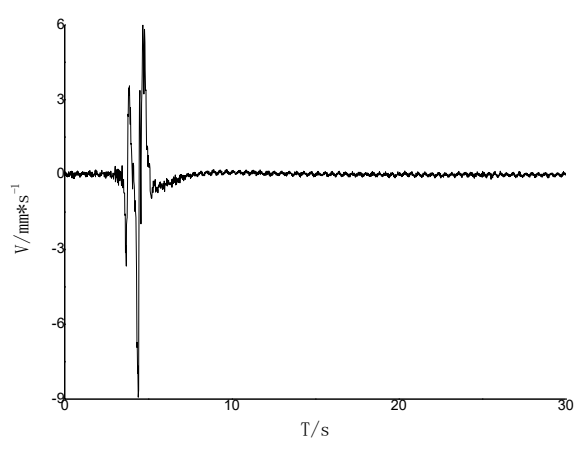

(a) Top

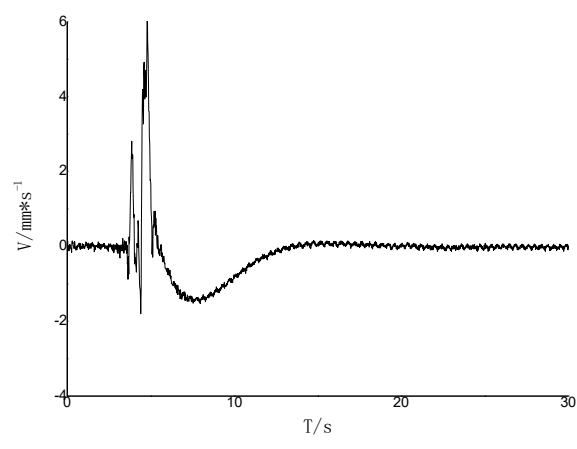

(b) Side

Fig.7 - Time history curve of vibration velocity under working condition 5 
Under working condition 6 (60t truck, filling height with $100 \mathrm{~cm}$ ), the vibration speed time history of pipe top and pipe side is as follows:

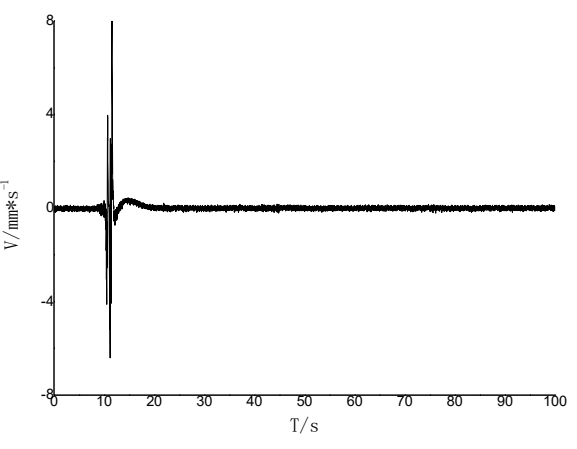

(a) Top

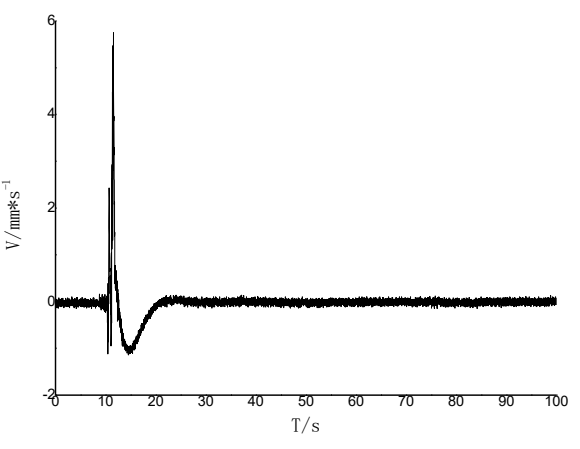

(b) Side

Fig. 8 - Time history curve of vibration velocity under working condition 6

The fast Fourier transform (FFT) spectrum analysis of the vibration velocity data of the pipe crown and the pipe side under the action of 20T vibrating roller can obtain the spectrum characteristic curve of the pipe top and the pipe side, as shown in Figure 8. In the figure, the horizontal axis is the frequency $(\mathrm{Hz})$, and the vertical axis is the vibration speed $(\mathrm{mm} / \mathrm{s})$.

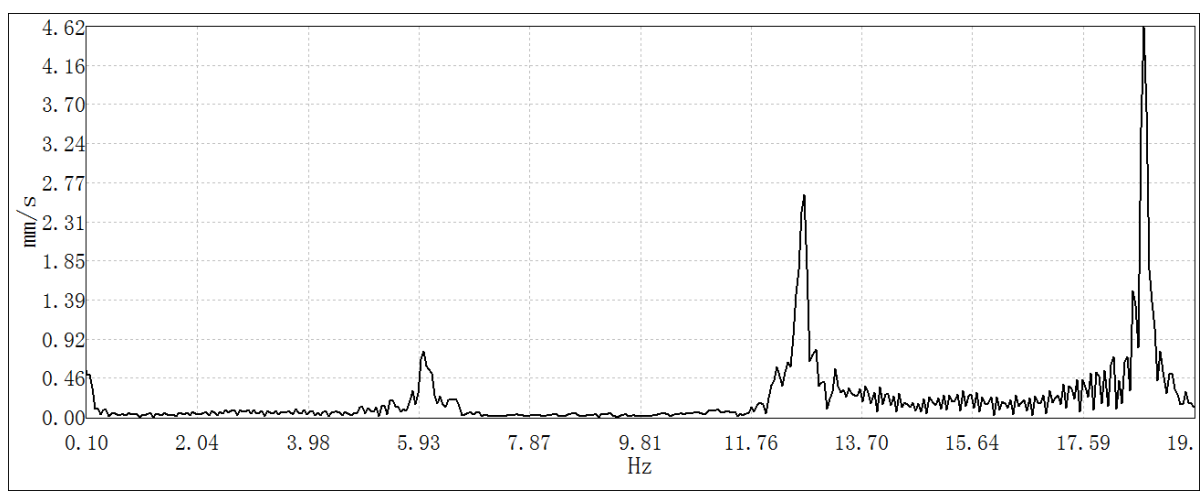

(a) V spectrum curve at the pipe crown

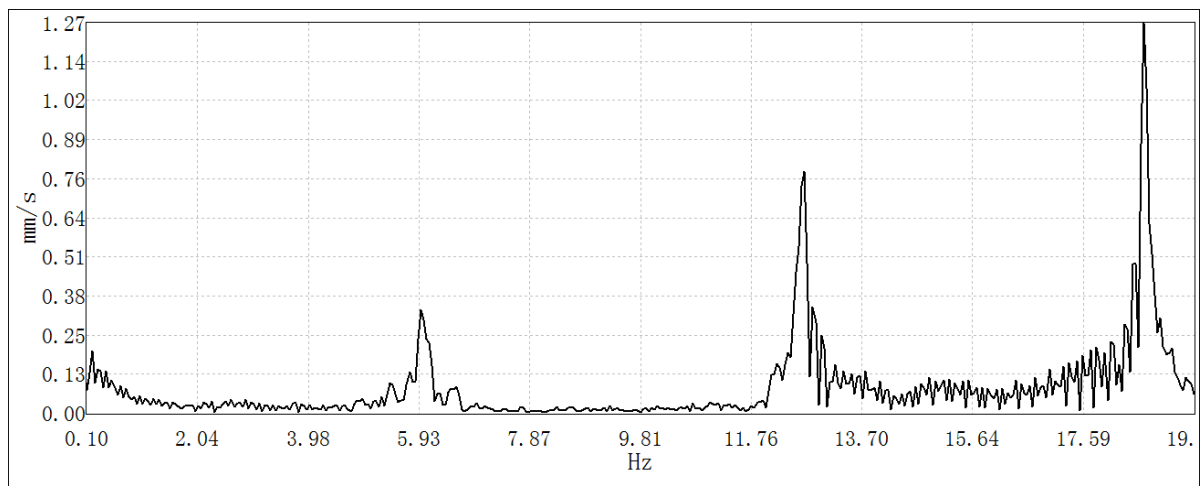

(b) H spectrum curve at the pipe spring line

Fig. 9 - Frequency spectrum of vibration velocity

The vibration speed data of the pipe crown and the pipe spring line are performed with FFT when the 40t heavy-duty engineering dumper is running, and the spectrum characteristic curve of the pipe top and the pipe side can be obtained, as shown in Figure 9. Where, (a) described the 
vertical spectrum curve at the pipe crown, and (b) described the horizontal spectrum curve at the pipe spring line.

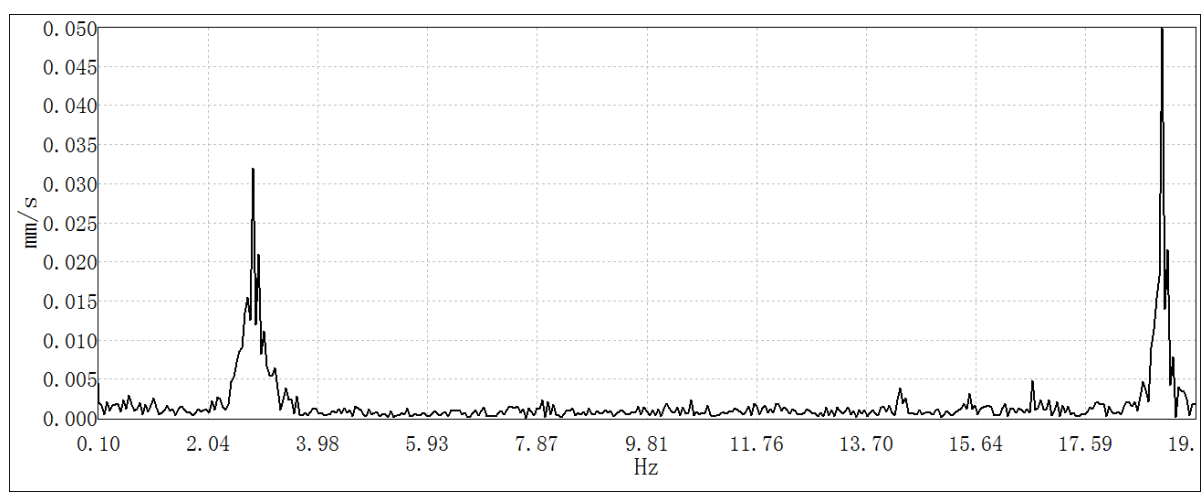

(a) V spectrum curve at the pipe crown

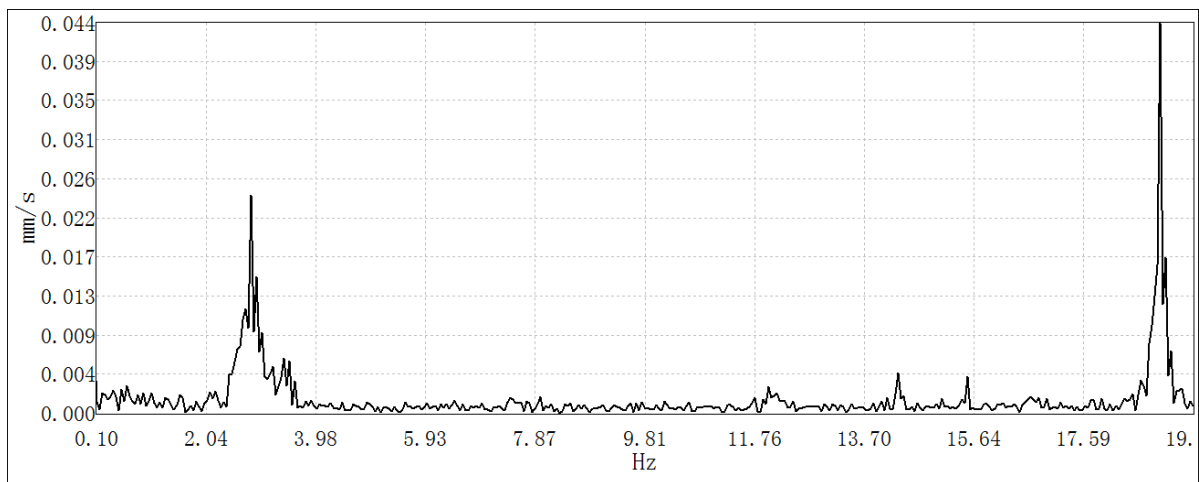

(b) $H$ spectrum curve at the pipe spring line

Fig.10 - Frequency spectrum of vibration velocity

FFT transform the vibration speed data of the top and side of the pipe when the 60t heavyduty engineering dumper is running, and the spectrum characteristic curve of the top and side of the pipe can be obtained, as shown in Figure 10. In the figure, the horizontal axis is the frequency $(\mathrm{Hz})$, and the vertical axis is the vibration speed $(\mathrm{mm} / \mathrm{s})$.

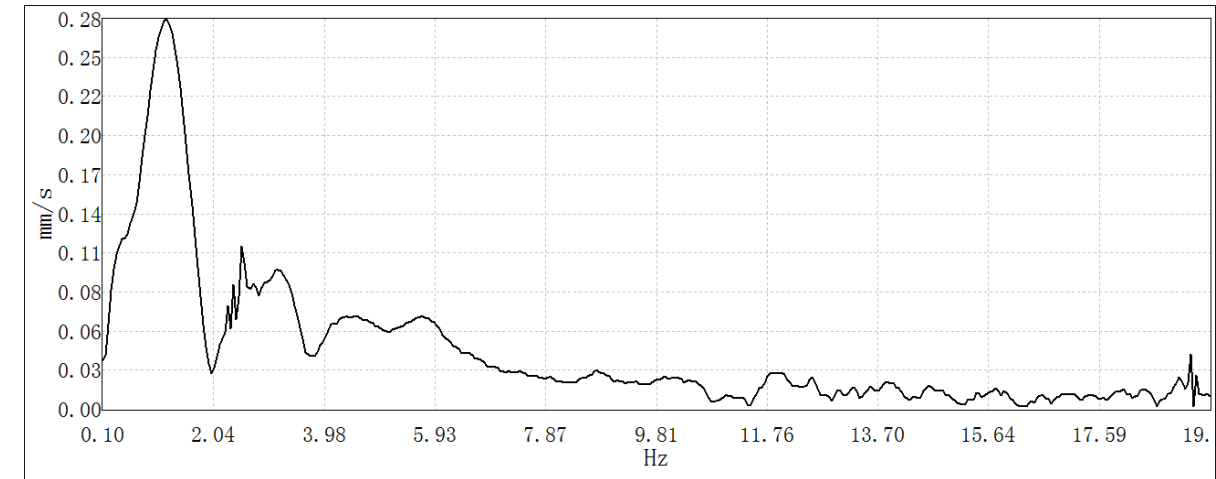

(a) $V$ spectrum curve at the pipe crown

Fig. 11 - Frequency spectrum of vibration velocity 


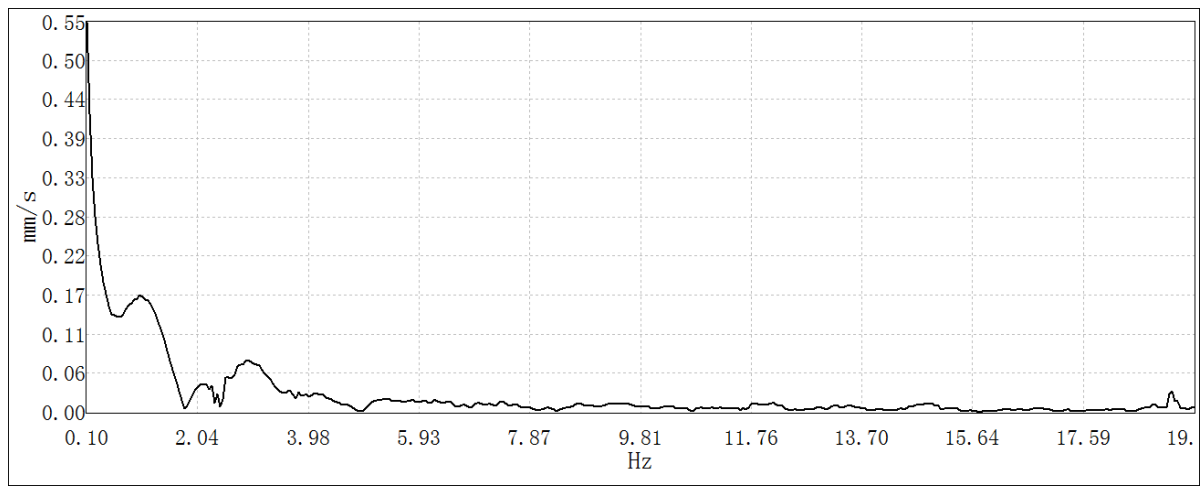

(b) $\mathrm{H}$ spectrum curve at the pipe spring line

Fig. 11 - Frequency spectrum of vibration velocity

As shown in Figures 3 to 11, when the 20t truck passes through the pipe culvert, the extreme value of the vibration velocity at the top of the pipe is obviously greater than that at the pipe side when the filling height is $80 \mathrm{~cm}$, but the extreme value of the vibration velocity at the pipe side is greater than that at the pipe top when the filling height is $100 \mathrm{~cm}$, which indicates that the filling height has a great influence on the vibration velocity at the pipe top. In other words, when the same weight vehicle passes through the pipe culvert, the higher the filling height is, the greater the consumption of vehicle vibration transmission to the pipe top is. Under condition 3 (truck 40t, filling height $80 \mathrm{~cm}$ ), the extreme value of vibration velocity at pipe top and pipe side has little difference, but the vibration response time at pipe side is significantly longer than that at pipe top; work condition 4, 5 and 6 are similar to this response.

\section{Results of modal analysis}

According to the results of modal analysis, the frequency and mode diagram of the first three main active modes are extracted. The first three natural frequencies are shown in Table 3. and Figure 12.

Tab. 3 - Natural frequency

\begin{tabular}{|c|c|}
\hline Order & $100 \mathrm{~cm}$ \\
\hline $1 \#$ & $26.602 \mathrm{~Hz}$ \\
\hline $2 \#$ & $32.022 \mathrm{~Hz}$ \\
\hline $3 \#$ & $35.786 \mathrm{~Hz}$ \\
\hline
\end{tabular}
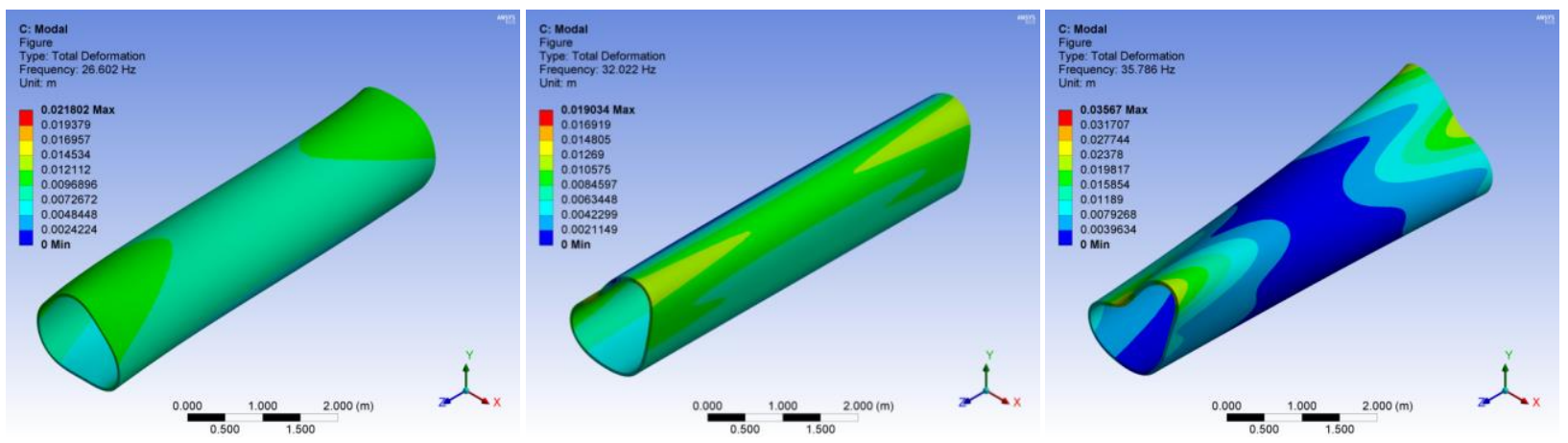

Fig. 12- The first third mode diagram 
In this paper, YES-DASP system is used to collect data, and GT-413 accelerometer is used as vibration sensor. The micro vibration speed signals of several common vehicles are collected. In the collected acceleration time history curve, select a representative section of load history curve a $(T)$, and input the PSD spectrum value into the workbench. Using workbench, the models with buried depth of 50, 80 and $100 \mathrm{~cm}$ under different working conditions are established respectively. After the acceleration PSD spectrum is input, the corresponding degree of freedom constraints are applied in the $X, Y$ and $Z$ directions of the numerical model, and then the acceleration excitation in the $Y$ direction is applied to each node of the whole model. In the analysis of calculation results, select representative points and draw their spectrum curve. In this paper, the top (V) point and the side $(\mathrm{H})$ point are selected as examples, where $\mathrm{H}$ and $\mathrm{V}$ represent the horizontal and vertical directions respectively. Under the excitation of heavy-duty vehicle with vehicle weight of $40 \mathrm{t}$ and vehicle speed of $30 \mathrm{~km} / \mathrm{h}$ to the pavement with buried depth of $80 \mathrm{~cm}$, the corresponding frequency response curve of the measuring point is shown in Figure 13 - Figure 21. Where, the horizontal axis represents time(s), and the longitudinal axis represents the displacement $(\mathrm{mm})$.

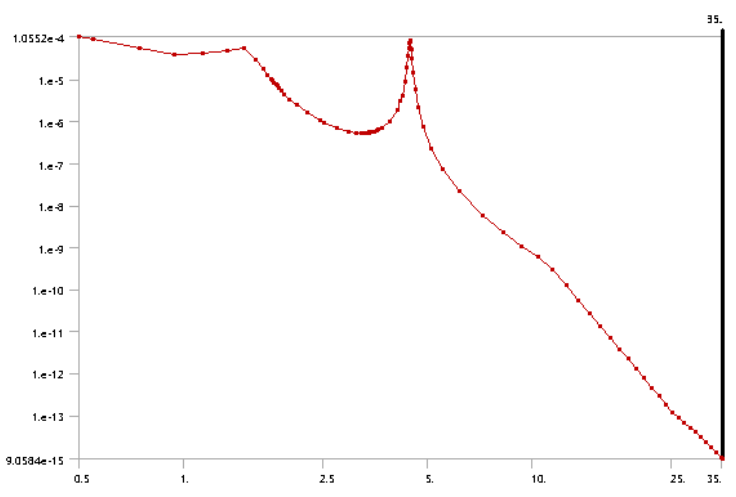

(a) $V$

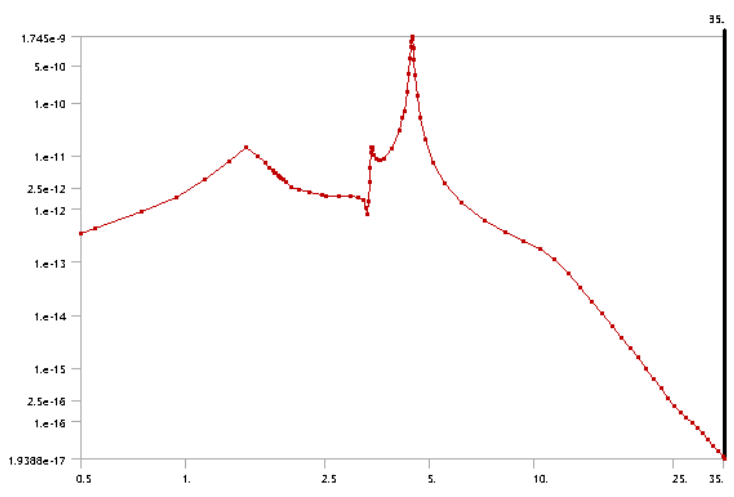

(b) $H$

Fig.13 - Response curve of spectrum displacement under $50 \mathrm{~cm}$ condition

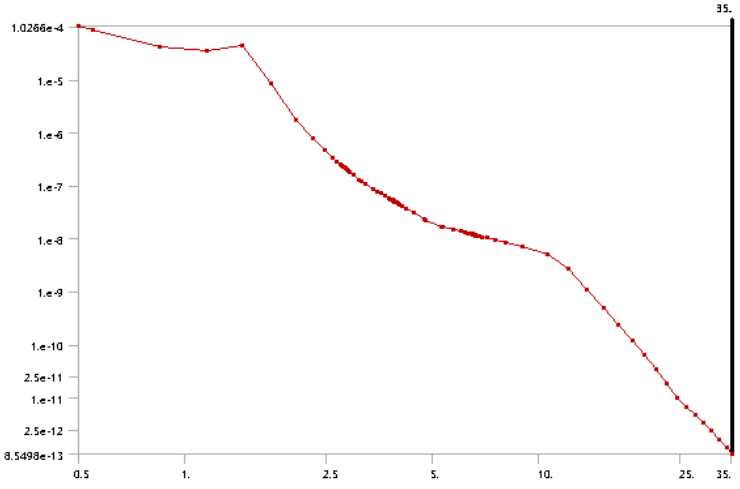

(a) $V$

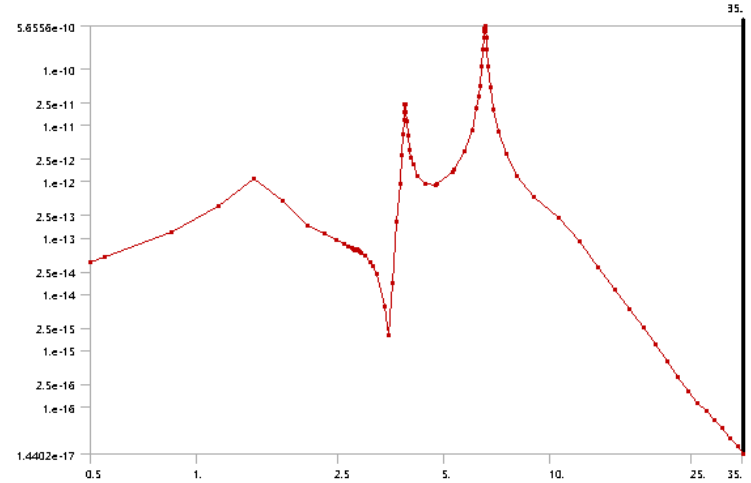

(b) $H$

Fig.14 - Response curve of spectrum displacement under $80 \mathrm{~cm}$ condition 


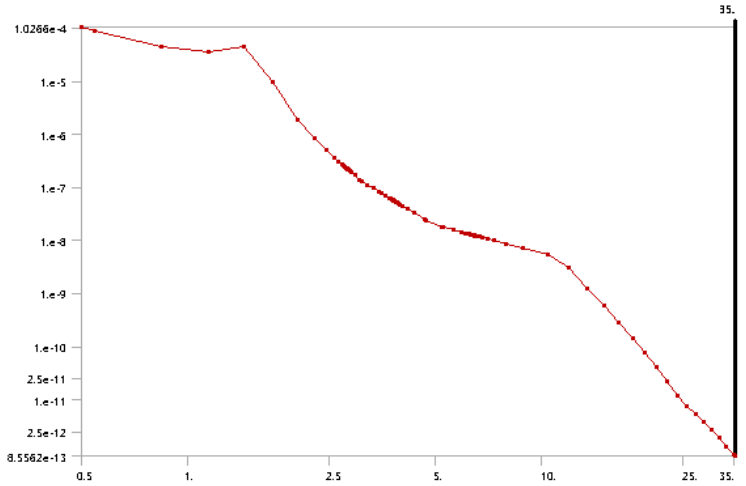

(a) $\mathrm{V}$

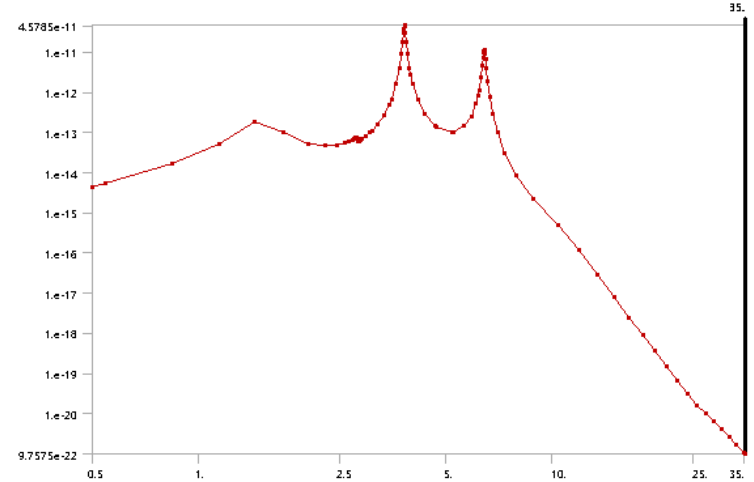

(b) $\mathrm{H}$

Fig. 15 - Response curve of spectrum displacement under $100 \mathrm{~cm}$ condition

The spectrum response curve of buried pipe under the excitation of vehicle type with vehicle weight of $60 \mathrm{t}$ and vehicle speed of $25 \mathrm{~m} / \mathrm{s}$ are as follow:

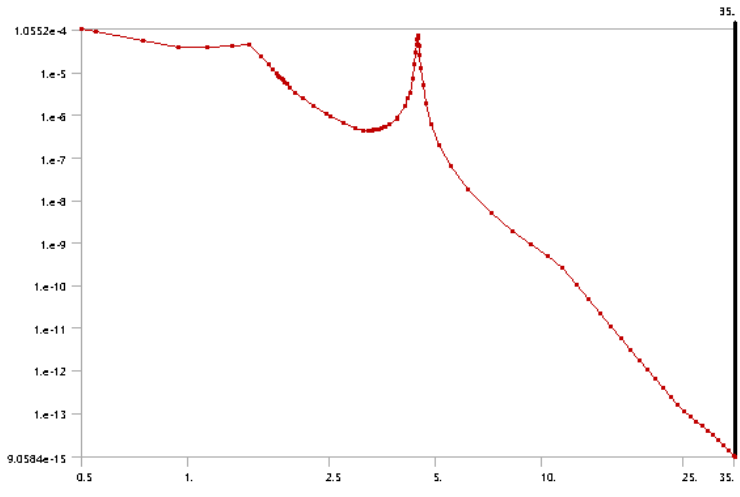

(a) $V$

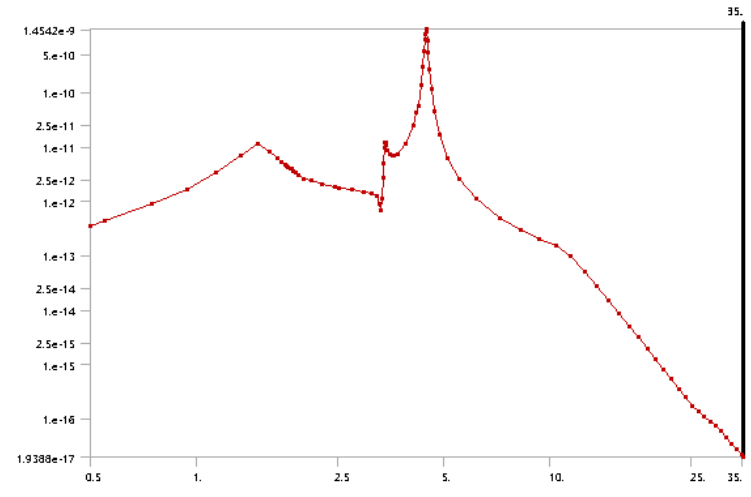

(b) $\mathrm{H}$

Fig. 16 - Response curve of spectrum displacement of tube under $50 \mathrm{~cm}$ condition

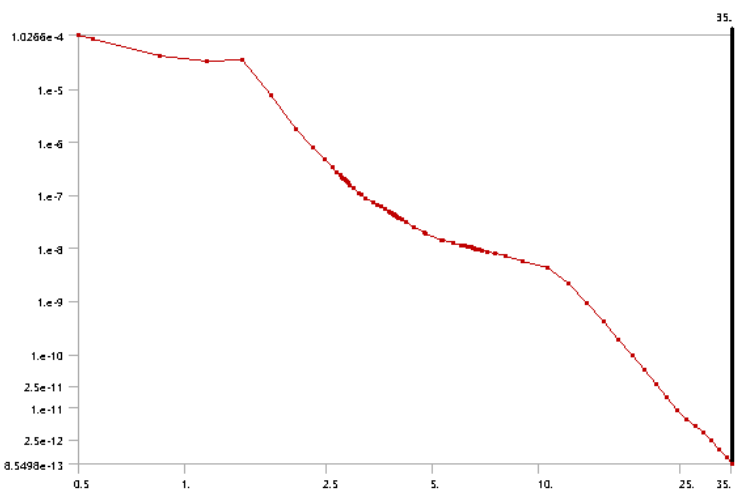

(a) $\mathrm{V}$

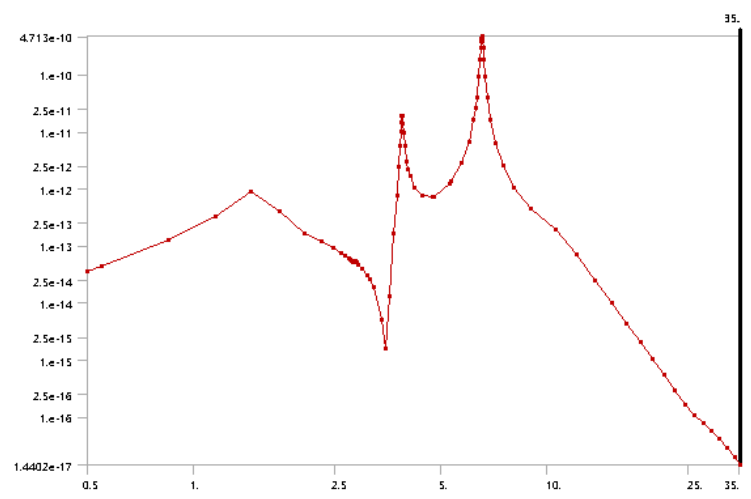

(b) $H$

Fig.17 - Response curve of spectrum displacement under $80 \mathrm{~cm}$ condition 
Article no. 17

CIVIL

ENGINEERING

THE CIVIL ENGINEERING JOURNAL 1-2021

JOURNAL

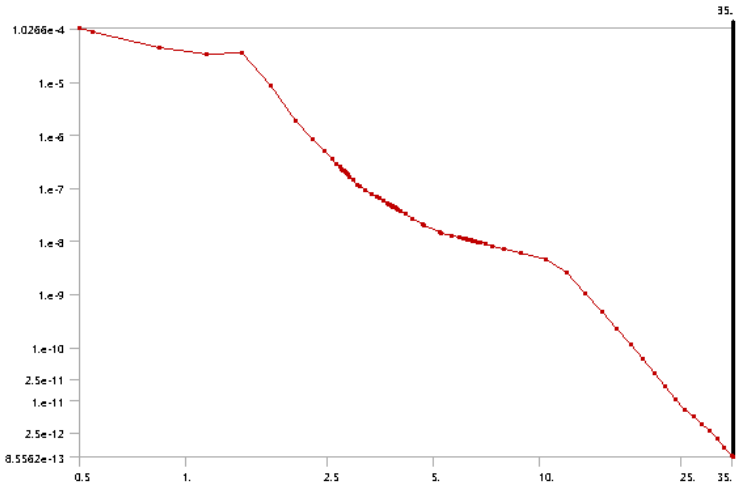

(a) $V$

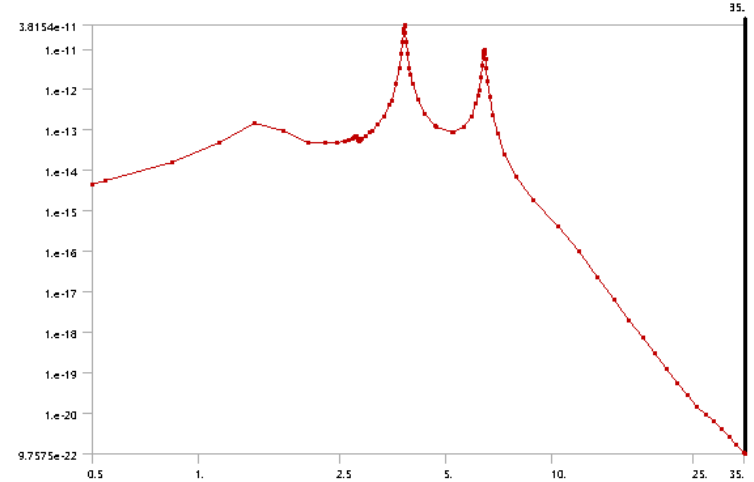

(b) $H$

Fig. 18 - Response curve of spectrum displacement under $100 \mathrm{~cm}$ condition

The spectrum response curve of buried pipe under the excitation of vehicle type with vehicle weight of $60 \mathrm{t}$ and vehicle speed of $20 \mathrm{~m} / \mathrm{s}$ are as follow:

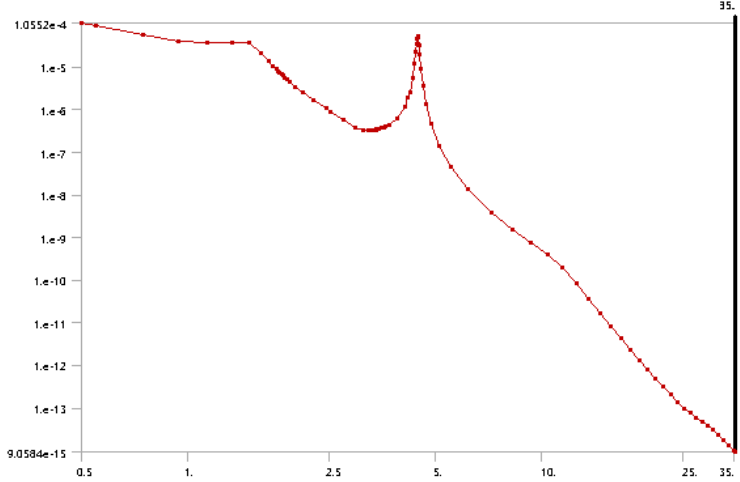

(a) $\mathrm{V}$

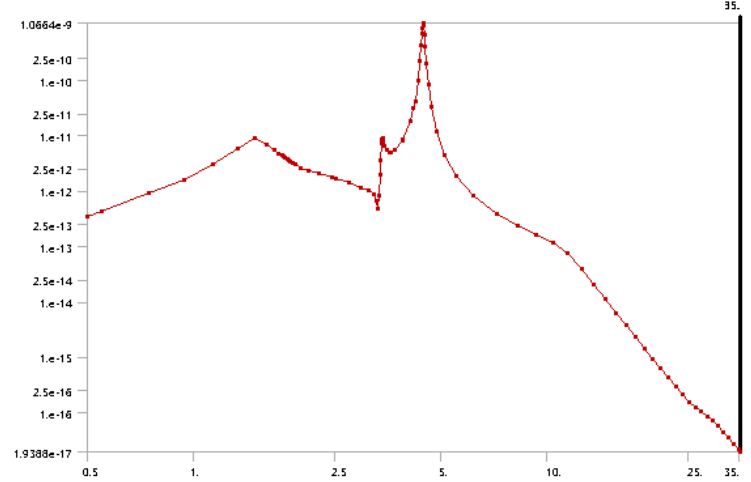

(b) $H$

Fig.19 - Response curve of spectrum displacement under $50 \mathrm{~cm}$ condition

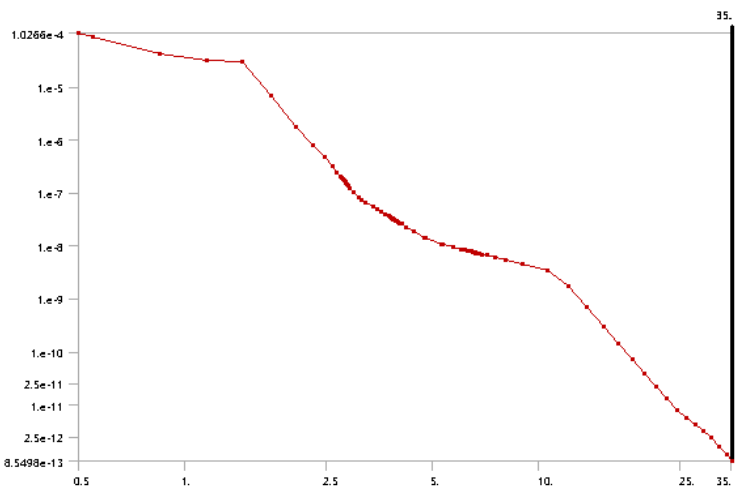

(a) $\mathrm{V}$

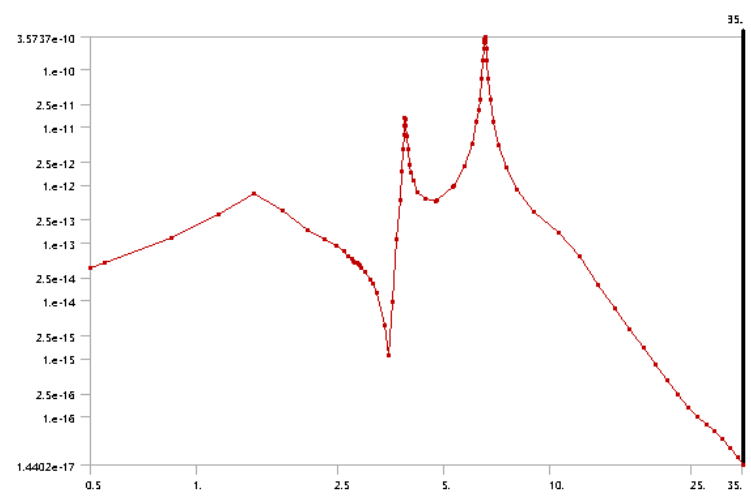

(b) $H$

Fig.20 - Response curve of spectrum displacement under $80 \mathrm{~cm}$ condition 


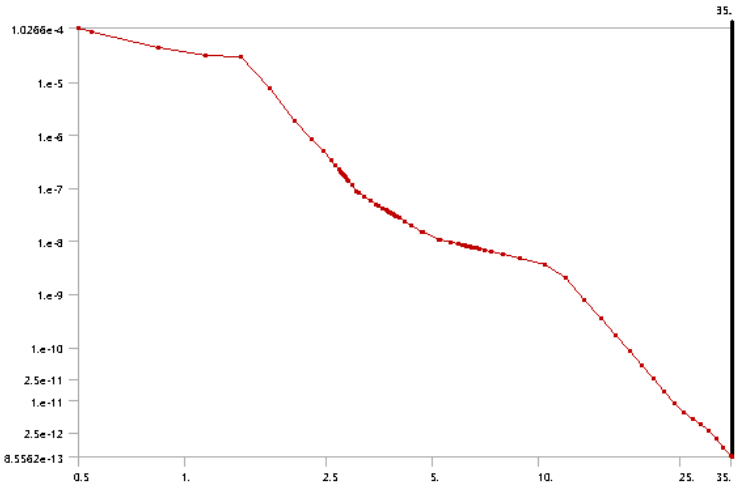

(a) $\mathrm{V}$

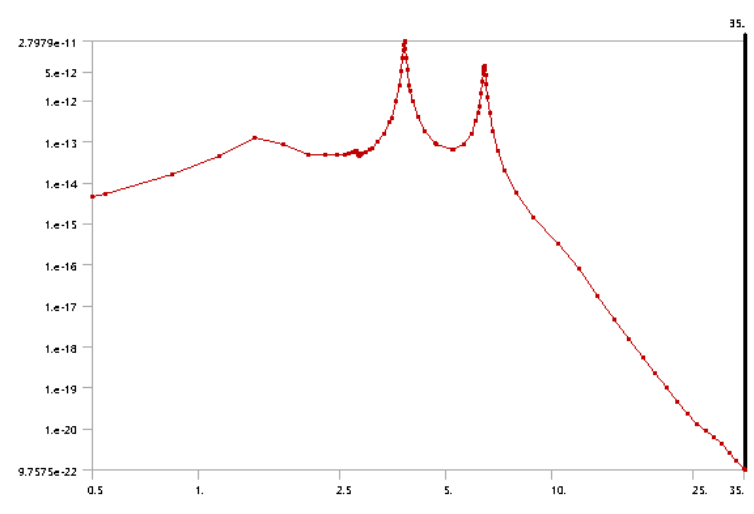

(b) $\mathrm{H}$

Fig.21 - Response curve of spectrum displacement under $100 \mathrm{~cm}$ condition

Under the work condition of the burial depth with $50 \mathrm{~cm}$ and the vehicle speed of $30 \mathrm{~m} / \mathrm{s}$, the peak values of displacement frequency and acceleration frequency of the pipe top are the largest, which are respectively $1.0552 \mathrm{e}-4\left(\mathrm{~m}^{2}\right) / \mathrm{Hz}$ and $5.2998\left(\mathrm{~m}^{2} / \mathrm{Hz}\right)$; when the burial depth changes from $50 \mathrm{~cm}$ to $80 \mathrm{~cm}$, the spectral response value of the pipe apex decreases accordingly When the buried depth changes from $50 \mathrm{~cm}$ to $80 \mathrm{~cm}$, the peak value of the frequency at the pipe side will decrease more than that of the buried depth from $80 \mathrm{~cm}$ to $100 \mathrm{~cm}$. The possible reason for this phenomenon is that with the increase of buried soil depth, the soil arching effect (uneven displacement or relative displacement between soil particles) of soil on the pipeline becomes more and more obvious, which changes the load diffusion angle; at the same time, it forms the supporting arch foot, which bears the automobile load together with the buried pipe [19,20,21]. For different buried depth, with the increase of vehicle speed, the peak value of displacement frequency and acceleration frequency corresponding to the pipe vertex and the pipe side point will also increase. As the vehicle speed increases, the vertical response of the vehicle becomes larger, and the increase of the vehicle speed makes the power spectral degree of the random dynamic load of the vehicle become larger, so does the dynamic response transmitted to the pipeline through the road. Table 4 shows the calculation results of pipe vertex and pipe side point under different working conditions.

Tab. 4 - The calculation results of spectrum response under different working conditions

\begin{tabular}{|c|c|c|c|c|c|}
\hline \multirow{2}{*}{ Working condition } & \multicolumn{2}{|c|}{$\begin{array}{c}\text { Peak value of displacement frequency } \\
\left(\mathrm{m}^{2}\right) / \mathrm{Hz}\end{array}$} & \multicolumn{2}{c|}{$\begin{array}{c}\text { Peak acceleration frequency } \\
/\left(\mathrm{m} / \mathrm{s}^{2}\right)^{2} / \mathrm{Hz}\end{array}$} \\
\cline { 3 - 6 } & & Top $(\mathrm{V})$ & Side $(\mathrm{H})$ & $T$ Top $(\mathrm{V})$ & Side $(\mathrm{H})$ \\
\hline \multirow{3}{*}{$30 \mathrm{~m} / \mathrm{s}$} & $50 \mathrm{~cm}$ & $1.0552 \mathrm{e}-4$ & $1.745 \mathrm{e}-9$ & 5.2998 & $1.0697 \mathrm{e}-3$ \\
\cline { 2 - 6 } & $80 \mathrm{~cm}$ & $1.0266 \mathrm{e}-4$ & $5.66 \mathrm{e}-10$ & $2.9801 \mathrm{e}-1$ & $1.5987 \mathrm{e}-3$ \\
\cline { 2 - 6 } & $100 \mathrm{~cm}$ & $1.0266 \mathrm{e}-4$ & $4.5785 \mathrm{e}-11$ & $2.8559 \mathrm{e}-1$ & $2.8863 \mathrm{e}-5$ \\
\hline \multirow{3}{*}{$25 \mathrm{~m} / \mathrm{s}$} & $50 \mathrm{~cm}$ & $1.0552 \mathrm{e}-4$ & $1.4542 \mathrm{e}-9$ & 4.4165 & $8.9141 \mathrm{e}-4$ \\
\cline { 2 - 6 } & $80 \mathrm{~cm}$ & $1.0266 \mathrm{e}-4$ & $4.713 \mathrm{e}-10$ & $2.4284 \mathrm{e}-1$ & $1.3322 \mathrm{e}-3$ \\
\cline { 2 - 6 } & $100 \mathrm{~cm}$ & $1.0266 \mathrm{e}-4$ & $3.8154 \mathrm{e}-11$ & $2.3386 \mathrm{e}-1$ & $2.4052 \mathrm{e}-5$ \\
\hline \multirow{3}{*}{$20 \mathrm{~m} / \mathrm{s}$} & $50 \mathrm{~cm}$ & $1.0552 \mathrm{e}-4$ & $1.0664 \mathrm{e}-9$ & 3.2388 & $6.537 \mathrm{e}-4$ \\
\cline { 2 - 6 } & $80 \mathrm{~cm}$ & $1.0266 \mathrm{e}-4$ & $3.5737 \mathrm{e}-10$ & $1.987 \mathrm{e}-1$ & $1.0102 \mathrm{e}-3$ \\
\cline { 2 - 6 } & $100 \mathrm{~cm}$ & $1.0266 \mathrm{e}-4$ & $2.7979 \mathrm{e}-11$ & $1.9226 \mathrm{e}-1$ & $1.8197 \mathrm{e}-5$ \\
\hline
\end{tabular}


As shown in Table 4, under the condition of buried depth of $50 \mathrm{~cm}$, the peak value of vertical displacement frequency at the top of the pipe is mainly concentrated in three frequency segments of $0.5 \mathrm{~Hz},(1-1.5) \mathrm{Hz}$ and $(4-5) \mathrm{Hz}$, the maximum displacement frequency peak value is $1.0552 \mathrm{e}-$ $4\left(\mathrm{~m}^{2}\right) / \mathrm{Hz}$; under the condition of the buried depth of $80 \mathrm{~cm}$, the peak value of the vertical displacement frequency of the pipe top is mainly concentrated in two frequency segments of $0.8 \mathrm{~Hz}$ and $(1-1.5) \mathrm{Hz}$, the peak value of the maximum displacement frequency is $1.0266 \mathrm{e}-4\left(\mathrm{~m}^{2}\right) / \mathrm{Hz}$; when the buried depth is $100 \mathrm{~cm}$, the peak value of the vertical displacement frequency of the pipe top is mainly $0.5 \mathrm{~Hz}$, the peak value of the maximum displacement frequency is $1.0266 \mathrm{e}-4\left(\mathrm{~m}^{2}\right) / \mathrm{Hz}$. This shows that with the increase of the filling height, the distribution range of the peak frequency of the vertical displacement on the top of the pipe decreases, and the peak frequency of the maximum displacement also decreases. It is similar to the peak value of displacement frequency on the tube side. The peak value of acceleration frequency at the top of the pipe decreases with the increase of filling height, but the peak value of maximum acceleration frequency at the side of the pipe reaches the maximum value when the buried depth is $80 \mathrm{~cm}$. In other words, the main factor influencing the apex value of culvert is the depth of fill, when it increases, causes the apex value to increase. Other important elements influencing the apex value are the vehicle speed. There is a positive correlation between the vehicle speed and the vibration response extreme of the pipe top and side.

\section{CONCLUSIONS}

In this paper, the dynamic response values of the glass sand pipe with buried depth of $80 \mathrm{~cm}$ and $100 \mathrm{~cm}$ under the weight of 20,40 and $60 \mathrm{t}$ truck are measured and analyzed through the field test. Then, according to the field situation, the finite element dynamic analysis model of GRP mortar pipe culvert is established by using the ANSYS Workbench finite element mechanical analysis program. The modal analysis of the buried GRP mortar pipe is carried out, and the main natural vibration frequency and the corresponding vibration mode diagram are obtained. On the basis of modal analysis, the dynamic response of GRP mortar pipe under different working conditions is studied by random vibration, and the following conclusions are obtained:

(1) The error is less than $15 \%$ by comparing the simulation value with the test value under the same working condition. The feasibility of using workbench random vibration module to analyze the frequency response of buried pipe is verified.

(2) The vehicle load is imposed as $20 \mathrm{t}$, $40 \mathrm{t}$ and $60 \mathrm{t}$ respectively, the vibration frequency of the glass sand pipe with buried depth of 80 and $100 \mathrm{~cm}$ is far less than the first three natural frequencies calculated by modal analysis. Therefore, when the filling height of the pipe culvert is $0.8 \mathrm{~m}$ and $1 \mathrm{~m}$, the roller will not resonate and damage the buried pipe under strong earthquake. After the soil foundation is compacted, the traffic of the heavy material truck can be restored.

(3) For the buried GRP mortar pipe under different working conditions, the frequency response of vertical vibration at the top of the pipe is generally greater than that of horizontal vibration

(4) With the increase of the buried depth, the frequency response value of the pipeline to the vehicle load decreases. When the buried height of the GRP mortar pipe is greater than $0.8 \mathrm{~m}$, the soil arching effect becomes more and more obvious, and the impact of the ground vehicle dynamic load on the vibration of the buried pipe can be ignored. For different buried depth, with the increase of vehicle speed, the peak value of displacement frequency and acceleration frequency corresponding to the pipe vertex and the pipe side point will also increase.

(5) A numerical model is established for the whole structure of the buried GRP mortar pipe with a buried depth of 50,80 and $100 \mathrm{~cm}$. The critical natural frequency is obtained by modal 
analysis. Based on the measured micro vibration data of the site, the vibration response frequency range of the key points of the pipe is obtained by workbench random vibration simulation. After comparison, the vibration frequency does not intersect and resonance will not occur.

In summary, the results concluded in this paper show that the feasibility of using Workbench random vibration module to analyze the spectrum response of buried pipelines. It provides basis for safety degree of engineering design, especially for safety problems under heavy load, as well as construction and application of GRP mortar pipe culverts. The further research focuses on the mechanical analysis and life estimation of the buried GRP mortar pipe under the earthquake load. And further optimize the pipeline structure to realize the wide application of GRP mortar pipe in the field of bridge and culvert engineering.

\section{ACKNOWLEDGEMENTS}

This research project is funded by Natural Science Foundation of Hebei (E2019402395).

\section{REFERENCES}

[1] Specification for Fiberglass (Glass-Fiber-Reinforced Thermosetting-Resin) Pipe and Pipe Fittings, Adhesive Bonded Joint Type, for Aviation Jet Turbine Fuel Lines[S]. ASTM, 2003.

[2] Test Methods for Constituent Content of Composite Materials[S]. ASTM, 2003.

[3] Newmark N M, Hall W J. Pipeline design to resist large fault displacement [J]. Earthquake Engineering Res Inst, 1975,416- 425.

[4] Parmelee R A, Ludtke C A. Seismic soil-structure interaction of buried pipelines [D]. Civil Engineering:Northwestern University, 1974.

[5] Zhang Tuqiao, Shao Weiyun.Numerical analysis of buried pipe characteristics [J].Journal of Zhejiang University(Science), 2000, 1(2):144-147.

[6] Zhang Tuqiao, Wu Xiaogang. A preliminary study on the longitudinal force analysis mode of pipelines under vertical loads [J]. Chinese municipal engineering,2001, 95(4):41-45.

[7] J.Lee. Strength of filament wound GRP tubes with axisymmetric steps[J].composite, 1989,20 (3) :234-243.

[8] Jeyapalan, J.K., et al .Analysis and design of RPM and other composite underground pipelines.Journal of Transportation Engineering,1990,115 (3):219-231.

[9] Xu Lei, Ye Zhicai, Ren Qingwen. Dynamic response analysis of buried fiberglass reinforced plastic sand pipe under earthquake load [J]. Journal of disaster prevention and mitigation engineering, 2012, 32 (04): 468-474.

[10] Manko Z, Beben D. Dynamic testing of a corrugated steel arch bridge. Can J Civ Eng 2008;35(3):246-57.

[11] Beben D, Manko Z. Dynamic testing of a soil-steel bridge. Struct Eng Mech 2010;35(3):301-14..

[12] Bayoglu Flener E, Karoumi R. Dynamic testing of a soil-steel composite railway bridge. Eng Struct 2009;31(12):2803-11.

[13] Jeyapalan, J.K., et al .Analysis and design of RPM and other composite underground pipelines.Journal of Transportation Engineering,1990,115 (3):219-231.

[14] Zhang Jiyuan, Wei Lianyu, Zhang Guopan, Chen Zhaonan, Zheng Yanjun. The flexure and deformation characteristics of buried FRP sand pipe in highway[J]. glass steel / composite material,2016 (10): 56-59.

[15] Liu Baodong, Yin Hang, Feng Zhimao, Wang Quanlu. Stress analysis on the construction process of soil corrugated steel plate arch bridge based on the soil and steel joint action model[J]. Beijing Jiaotong University Journal,2009,33(04) : 66-68. 
Article no. 17

CIVIL

ENGINEERING

THE CIVIL ENGINEERING JOURNAL 1-2021

JOURNAL

[16] Li Mingyang, Chen Guohua. Finite element analysis of buried polyethylene gas pipeline under traffic load [J]. plastic industry.2009 (09), 37(09) : 30-33..

[17] Xu Jingjing. ANSYS 13.0 Workbench numerical simulation technology[M]. Beijing: China Water Conservancy and Hydropower Press, 2012.

[18] Gao Guangyun, Nie Chunxiao, Li Shaoyi. Micro vibration test and numerical analysis of the electronics factory building [J]. Site Investigation Science and Technology,2011(03):51-55.

[19] Wu Yanling. Stress and deformation characteristics of highway steel corrugated pipe culvert and its application research [D]. Chang'an :Chang'an University,2012.

[20] B.H.Kjartanson,GA.Heilers,R.A.Lohnes,F.W.Klaiber.Soil-Structure Interaction Analysis of Longitudinal Uplift of Culverts[J].Journal of Geotechnical and Geoenvironmental Engineering, 1998, 124(2):128-139

[21] Feng Li. Mechanical performance analysis of corrugated pipe culvert with soil interaction. [D]. Beijing:BeijingJiaotong University,2010. 